\title{
O ensino para educação \\ das relações étnico-raciais: um olhar para o cotidiano escolar
}

Roseane Maria de Amorim*

\section{RESUMO}

Abrindo caminho para o estabelecimento de um amplo debate em nível nacional sobre as questões referentes à situação do negro e do afro-descendente na sociedade brasileira foi sancionado pelo Governo Federal a Lei 10.639/2003 que altera a LDB 9694/96. Neste sentido, proponho a discussão das diversas identidades dos educandos e educandas da Educação infantil ao Ensino Médio desde a introjeção de valores considerados negativos, alimentado no dia-a-dia por processos sociais, até a consolidação de uma identidade afrocentrada, valorizando também a inclusão das raízes européias e indígenas. Desta forma, este trabalho possibilita uma reflexão sobre o ensino da educação étnico-raciais nos diversos níveis de ensino, em diferentes componentes curriculares e especialmente na disciplina de História.

Palavras-chave: Educação, Relações étnico-raciais, Currículo, Ensino de história.

As feridas da descriminação racial se exibem ao mais superficial olhar sobre a realidade do país.

Abdias do Nascimento

\section{Introdução}

É de conhecimento da sociedade em geral e dos educadores que 0 Brasil precisà reinventar a sua história. Construir uma nação mais justa com oportunidades iguais para todos independente do grupo étnico, raça e condições

* Mestre em Educação pela UFPE. Doutoranda em Educação - UFPE - Assessora de História da Pref. de Jaboatão dos Guararapes. Professora da Faculdade de Timbaúba - FAEST -PE. 
sociais. Com base nessa necessidade o Governo Federal instituiu a Lei 10.639/ 2003 que estabelece as Diretrizes Curriculares Nacionais para a Educação das Relações Étnico-raciais e para o ensino da História e Cultura Afro-brasileira e Africana. Diretrizes são dimensões normativas, reguladoras de caminhos, embora não fechadas para que possa, com base nas determinações iniciais, tomar novos rumos.

Diante deste contexto a escola na atualidade tem como desafio a inclusão das diferentes pessoas, seja no âmbito das relações, seja no atendimento das necessidades individuais e coletivas. Neste sentido, faz-se necessário que todos os envolvidos com a educação estejam preparados para vivenciar no cotidiano das instituições de ensino alternativas de práticas que ajudem a formar seres humanos mais solidários e que saibam conviver com as diferenças.

Desta forma, este texto pretende subsidiar a prática educativa, tendo como recorte as relações étnico-raciais e instigar a busca pela pesquisa, pelo novo (sem deixar de encontrar no velho os elementos importantes para enfrentar a realidade presente) buscando o aprimoramento do trabalho que realizamos com as crianças, jovens e adultos das diversas rede de ensino. 0 intuito é a inserção dessa temática nos seguintes aspectos: a) socialização e visibilidade da cultura negro-africana; b)contribuir para construção de material didático pedagógico que contemple a diversidade étnico-racial; c) valorização das identidades presentes nas escolas em todas as atividades desenvolvidas; d) promover espaço de reflexão sobre os diversos tipos de preconceitos presente no cotidiano escolar.

Em linhas gerais buscamos instigar um diálogo com os/as professores/as, diretores/as, coordenadores/as, assessores/as para que encontrem alternativas e proponham ações nas quais as questões étnico-raciais sejam objeto de estudo com os educandos e educandas, no sentido de combater qualquer forma de discriminação. Assim, esperamos que este texto seja um elemento que venha a contribuir com a formação de todos aqueles que estão envolvidos com a educação.

0 texto será estruturado da seguinte forma: inicialmente abordaremos as questões das relações étnico-raciais em todos os níveis e modalidade de ensino, acentuando a especificidade de cada momento da formação dos indivíduos. A seguir apontaremos algumas reflexões sobre a questão da identidade voltado especificamente para a disciplina de História e sugerimos 
atividades que podem e devem ser adequadas de acordo com a realidade da escola. Por último, com as considerações finais, acentuamos a discussão da importância desta temática para fortalecer as identidades dos sujeitos que estão envolvidos com o processo educativo.

\section{A Educação Infantil e a educação para as relações étnico-raciais}

Cada fase da vida necessita de um atendimento específico, requerendo de quem lida com o ser humano uma atenção especial às necessidades que caracterizam cada momento. No período em que consideramos a educação infantil (zero a seis anos), é fundamental que o afeto ajude a criança a construir uma identidade positiva sobre si e o respeito em relação ao outro. Neste sentido, é importante desde os primeiros anos de escolarização que os educandos e educandas reflitam sobre si e sobre o mundo que o rodeia. Como afirma SANTANA (2006, p.29)

É com o outro, pelos gestos, pelas palavras, pelos toques e olhares que a criança construirá sua identidade e será capaz de reapresentar o mundo atribuindo significados a tudo que a cerca. Seus conceitos e valores sobre a vida, o belo, 0 bom, o mal, o feio, entre outras coisas, começam a se constituir nesse período.

Faz-se necessário que o/a educador/a esteja atento para as relações que permeiam o cotidiano escolar e que no currículo real (aquilo que realmente é vivenciado na escola) promova o diálogo de forma lúdica e divertida de acordo com a faixa etária das crianças. É preciso que, desde cedo, a diferença seja objeto de estudo pois reconhecer as diferenças é um passo fundamental para a promoção da igualdade, sem a qual a diferença poderá ser transformada em desigualdade.

É importante que a educação infantil, responsável primeiramente pela dimensão da socialização e da vivência cultural, privilegie a temática diversidade no seu currículo. É a partir de atividades que oportunizem o pensar em relação as ações do cotidiano que as crianças, desde o início, vão se vendo enquanto sujeitos históricos pertencentes a determinados grupos.

Dados recentes da Unicef (2006) vêm mostrando que as crianças negras 
e indígenas são os segmentos mais excluídos do acesso à educação, na faixa etária de zero a seis anos. Um outro elemento importante que é visível aos olhos dos educadores é que a maioria dos discentes que freqüientam as escolas públicas são da cor negra vivendo em condições difíceis de sobrevivência.

Diante dessa realidade, o/a professor/a precisa está preparado/a para efetivar encaminhamentos que ajudem o discente a pensar sobre si, sobre o outro e sobre o mundo. Compreendemos que as pessoas podem viver e serem diferentes. Nesse sentido, desde pequenas as crianças precisam refletir sobre as diferentes formas de atuar na sociedade e compreendê-la. Por meio da literatura infantil o docente poderá levantar questões que façam sentido para o educando e educanda. Um ensino com base na reflexão preparará o aluno e a aluna para o Ensino Fundamental de forma que os mesmos serão sujeitos mais participativos e dinâmicos. Além de promover o gosto pela escola.

\section{A identidade dos estudantes do Ensino Fundamental}

Quando nos referimos aos estudantes do Ensino Fundamental pensamos em crianças e adolescentes de 7 a 14 anos de idade, estendendo esta faixa etária até aproximadamente 17 anos, em função da realidade educacional brasileira. Entretanto, um olhar cuidadoso para o cotidiano escolar nos mostra que estes educandos dentro da complexidade humana têm suas próprias características. Amam, pensam, criam odeiam, têm sonhos, sofrem e fazem sofrer, têm aparência física e pertencimento étnico-racial, posturas, memória, conflitos, afetos e saberes inscritos no seu corpo e em sua personalidade. Dessa forma, não podemos negar que a violência embutida no contexto brasileiro em diferentes faces vem construindo jovens individualistas e cheios de desejos de consumo.

É com este olhar para educandos concretos com sentimentos conflituosos que a escola contribui na formação de seres humanos pensantes e responsáveis pelas suas ações. Entretanto, para atingir esse fim faz-se necessário que as aulas e 0 ambiente escolar instiguem a reflexão, a leitura, a verdadeira pesquisa e a produção. Neste sentido, a prática da sala de aula não pode está pautada apenas em cópia do que é registrado no quadro pelo docente, na leitura e respostas das questões do livro didático. É preciso atividades nas quais os alunos e as alunas utilizem diversas linguagens, buscando possíveis respostas para os 
problemas da realidade em que estamos inseridos. Um trabalho nesta perspectiva exige a cooperação dos docentes e que os mesmos tenham uma identidade com a profissão para que possam juntos encontrar alternativas possíveis dentro de um quadro assustador que estamos vivendo.

\section{A pesquisa como fonte inspiradora para o conhecimento da realidade do Ensino Médio}

A realidade educacional do país aponta a necessidade de partir do projeto político-pedagógico das escolas, articulando os objetivos estabelecidos para o Ensino Médio, de acordo com a Lei de Diretrizes e Bases da Educação Nacional - LDB 9.394 de 1996. Neste sentido, é preciso que os adolescentes e jovens desta etapa de ensino tenham a oportunidade de pesquisar e de aprofundar os conhecimentos que tiveram no período anterior.

A pesquisa precisa ser entendida não como sinônimo de cópia de autores de livros didáticos mas sim, como resolução de um problema que inquieta professores/as e educandos. Os jovens por natureza gostam de desafios e portanto, torna-se necessário entender a categoria social da juventude como construção cultural em sua pluralidade e diversidade.

Neste contexto de construção da identidade do ser jovem é que se instaura a relação do eu com o outro. É a ação do olhar sobre o eu que possibilita a existência do como somos (TODOROV apud SOUZA 2006). Para compreender os alunos e alunas do Ensino Médio e suas diferenças, é necessário pensar o processo de construção do conhecimento desses sujeitos, sob o pressuposto do respeito a singulariedade dessa etapa de vida, sua relação com a identidade, a autonomia, a interação com a comunidade e com o mundo do trabalho.

Isso implica considerar que a escola tenha um projeto que contemple um currículo que

- Propicie ao educando a gestão do ensinar e do aprender, consoante com sua identidade e objetivos da modalidade de ensino;

- Enfatize 0 respeito pela dignidade humana, a igualdade de direitos e deveres e a co-repsonsabilidade pela vida social, como elemento que orientam a seleção de conteúdos e a organização de situações de aprendizagem.(SOUZA, 2006)

Neste ponto de vista, torna-se fundamental conhecer nossos alunos e alunas 
do Ensino Médio, possibilitar as discussões e inserção das Diretrizes para a Educação das Relações Étnico-Raciais para o Ensino de História e Cultura Afro-brasileira como elemento indispensável para pensar sobre a nossa própria formação. Somos todos brasileiros, mas com história e antepassados diferentes e ao mesmo tempo com um passado comum. Buscar no presente, o que não passou, é fundamental para a compreensão dos problemas que enfrentamos na atualidade.

\section{A Educação de Pessoas Jovens e Adultos: perspectivas e possibilidades}

A clientela de Jovens e adultos (EJA) é bastante diversificada, como o próprio nome diz, é formada por jovens e adultos, trabalhadores informais do campo e da cidade, indígenas, operários, sindicalistas, mães, pais desempregados, negros, afro-descendentes e brancos. Acreditamos que todo educador ao trabalhar com EJA deveria fazer as seguintes indagações: a) Quais as possíveis estratégias que podem ser utilizadas na minha prática no sentido de atender as necessidades específicas do grupo com o qual trabalho? Como melhorar a auto-estima destes jovens e adultos? De que maneira podese minimizar a evasão escolar? São indagações que não têm uma única resposta e precisa ser bem refletida.

Consideramos essa modalidade de ensino não como compensatória, de aceleração dos estudos de sujeitos que não tiveram oportunidade da escolarização ou que evadiram dos bancos escolares por não se adequarem à escola, e sim, como sujeitos que têm direito de desenvolver suas potencialidades. Como afirma PIRES (2006, p.100-101)

repensar a EJA numa perspectiva da educação anti-racista requer criar formas mais democráticas de se implementarem as ações e projetos para esse público, pautando a multiplicidade do tripé espaço-tempo-concepção na sua organização e desenvolvimento.

Dentre os desafios colocados para a EJA, estão o de possibilitar a inclusão do debate sobre a questão racial não apenas como tema transversal, mas como discussão, problematização e vivências para pensar sua própria vida dado o perfil do público que é majoritariamente negro. 
Assim, o/a educador/a de EJA necessita ter em mão textos de literatura afro-brasileira que contenham as seguintes características:

- Que apresentem ilustrações positivas de personagens negros;

- Cujos conteúdos remetam ao universo cultural africano e afro-brasileiro;

- Em que as tessituras realizadas durante a leitura possam contribui para elevação da auto-estima dos /as jovens e adultos.

Desta forma, a concepção e os princípios norteadores dessa temática não pode ser algo pontual é necessário um planejamento e elaboração de projetos didáticos que permitam a reflexão durante todo processo de aprendizagem do educando.

As matérias que compõem o ensino devem tratar desse assunto em diferentes ângulos e perspectivas. Faz-se necessário que o ensino discuta sobre os problemas que estão presentes no cotidiano. Por sua vez, a disciplina de História poderá ajudar muito no enfretamento da questão do preconceito e da discussão da situação do negro no Brasil ontem e hoje. Assim, apontaremos abaixo algumas considerações sobre o ensino da História e como a mesma poderá ajudar na formação da identidade positiva dos negros e negras no nosso país.

\section{Ensino de História e a construção das identidades}

No decorrer dos anos 80 e 90 do século XX, o debate colocou a necessidade de uma reavaliação do ensino de História, que passou a ser discutido em inúmeras abordagens. Estudiosos como BITTENCOURT, ROCHA e KARNAL $(1998,2005,2002,2003)$ apontam para redefinição da seleção dos conteúdos e da metodologia aplicada em sala de aula. 0 trabalho por conceitos, o uso de diversas linguagens no ensino e as atividades vivenciadas em sala de aula com base em documentos, foram algumas das saídas encontradas.

0 rompimento do ensino pautado numa História repetitiva, enfadonha sem sentido para o aluno é imprescindível. SCHMIDT e CAINELLI (2004, p. 30) apontam para a necessidade do professor e da professora ajudarem os educandos e educandas a aprenderem a pensar historicamente. Levantando problemas, questionando os documentos investigados e produzindo sua própria síntese sobre o que está sendo aprendido e ensinado. 
Ensinar História passa a ser, então, oportunizar ao aluno e a aluna as condições para aprender. Aprender a pensar sobre si mesmo, sobre a realidade em que estão inseridos e sobre as situações culturais, econômicas, sociais em que estamos envolvidos.

Entretanto, romper com o modelo de escola que temos não é uma tarefa simples. A formação dos docentes de História com base na estrutura francesa de divisão histórica em quatro grandes períodos (História Antiga, História Medieval, História Moderna e História Contemporânea) é o primeiro entrave a ser enfrentado. Um trabalho com base na problematização, na construção de conceitos e na utilização de fontes variadas exige além de materiais didáticos específicos um professor e uma professora pesquisadora e conseqüentemente com tempo para estudo.

Os alunos e alunas na atualidade fazem perguntas inocentes como: para que estudar História? Se o importante é viver o presente. Este questionamento nos levar a pensar a finalidade desta disciplina para a formação dos jovens.

Um ensino de História baseados em conceitos exige dos docentes pelo menos duas questões: que o professor e a professora partam do conhecimento prévio do aluno e da aluna, sem ficarem restritos a representação do estudante. E a segunda questão, ligada a primeira, requer que o docente ensine o educando e a educanda a tirarem suas próprias conclusões sobre os fenômenos e objetos estudados. No dizer de SCHMIDT e CAINELLI (2004, p.63) a construção de conceitos

é um processo cognitivo e articulado, já que os conceitos não são autônomos. Eles articulam-se, contrapõem-se e associam-se de forma solidária, pela acomodação e pela sua relação dialógica com um campo de conhecimento, uma relação com as representações já elaboradas pelos alunos, para modificá-las.

Dentro desta perspectiva o currículo para o ensino desta disciplina foi sendo redefinido, novos debates surgiram apontando para a problemática entre identidade e diferença. Por sua vez, os Parâmetros Curriculares Nacionais e as novas propostas pedagógicas das Redes de Ensino propõem uma História sociocultural com base em eixos temáticos e História temática lançando novos desafios aos educadores. Entretanto, não significa que essas novas propostas curriculares estejam sendo colocadas em prática em sua totalidade. 0 hibridismo 
da prática pedagógica dos docentes, como eles organizam os conteúdos e as condições impostas geram incertezas e medos, não proporcionando inovações.

Além de que, uma proposta pedagógica ou curricular por si só não garante mudanças efetivas nas salas de aula. Permanências e mudanças vão se dando ao mesmo tempo no processo educacional brasileiro (AMORIM, 2004).

Em relação ao ensino da História alguns estudiosos da área (BITTENCOURT, KARNAL, 2003) apontam que esta disciplina está associada à construção da identidade nacional. A língua é um instrumento prioritário para a unidade do país. Junto com ela elaboram-se os símbolos e os hinos, além de inserir os mitos heróicos remetendo a um momento crucial do passado.

Assim, no decorrer dos tempos os cultos aos heróis e festas cívicas são alguns dos valores que perpassaram e ainda perpassam o cotidiano escolar. A afirmação da identidade nacional é histórica, situada num ponto e tempo específico. Enfim, aquilo que somos marca o encontro do nosso passado com as relações sociais, culturais e econômicas. É o ponto de intersecção com 0 mundo que nos rodeia. (WOODWARD, 2006).

A história construída por mulheres e homens simples é banida das salas de aulas. Sabe-se que muitas críticas já foram feitas com respeito a essa problemática. Entretanto, ficam dúvidas sobre as possíveis saídas para ensinar a história no nosso país. Que caminhos os docentes precisam trilhar? Que grupos étnicos precisam ter voz no ensino? Como e de que forma introduzir as identidades que são excluídas no currículo formal? Que questões e temáticas precisam fazer parte do currículo real dos docentes de História? Que situações didáticas os professores e professoras têm realizado para mediar as contradições e conflitos que permeiam o ambiente escolar?

LOBO (2005, p.49) afirma que o currículo, "é uma arena onde se debatem idéias e práticas que acabam refletindo-se na estruturação de identidades." É preciso ir além, compreender o que está oculto, o que está por trás dos diversos conteúdos. Desnaturalizar o currículo formal, que ao longo do processo educacional foi considerado pronto, acabado e verdadeiro, passa pela necessidade de compreensão dos docentes de que os conteúdos trabalhados são historicamente selecionados de acordo com os interesses de quem está no poder. SILVA (1995, p.196) é enfático quando afirma que: 
o currículo, ao lado de muitos outros discursos, nos faz ser o que somos. Por isso, o currículo é muito mais que uma questão cognitiva, é muito mais que uma construção de conhecimento, no sentido psicológico. O currículo é a construção de nós mesmos como sujeitos.

Assim, é importante ressaltar que estudar as diversas identidades dos sujeitos leva-nos a compreender melhor a realidade do nosso país e apontar saídas para uma sociedade com mais igualdade social. Ouvir as diversas vozes que estão presentes no cotidiano escolar nos aproxima dos problemas sociais que assolam a nossa nação.

\section{7 -Sugestões de atividades voltadas para as questões étnico-raciais}

0 conjunto de atividades sugeridas neste texto precisa ser selecionada e ampliada pelos docentes dependendo da modalidade, da (s) série (s) e etapas de ensino em que o docente está envolvido. Uma mesma proposta pode ser adaptada para vários contextos dependendo das condições da escola, do professor e da professora e dos objetivos estabelecidos. Com esse argumento, a título de sugestões propomos a partir da análise da literatura da área alguns encaminhamentos para a prática docente.:

a) Possibilitar o acesso em sala de aula de alguns brinquedos de todas as cores (inclusive bonecas e bonecos da cor negra) e solicitar que as crianças façam a sua escolha. Iniciar uma debate sobre a necessidade de entender a diferença pois a própria natureza é diversa. Reflitir com as crianças as diferenças presentes na própria sala de aula. Produzir texto individual ou coletivo sobre as conclusões chegadas;

b) Solicitar aos alunos e alunas que desenhem várias árvores. Socializar a produção e realizar um passeio pelo bairro verificando os tipos de árvores e plantas. De volta á sala levar vários desenhos de árvores e debater sobre as diferenças;

c) Estudar os negros não apenas a partir da escravidão mas, retomar as diversas etnias do continente de origem desde a formação dos primeiros homens sapiens. Discutir o continente africano após o processo de 
descolonização no final do século XX e as consequiências para a África atual; Levar notícias de jornais que tratam da temática na atualidade. Comparar dados de pesquisas recentes.

d) Construir cartazes mostrando a atuação dos negros em diversos campos: moda, política, literatura, ciência, esportes, música, educação etc.;

e) Construir um grande mural mostrando as diversas identidades e diferenças na formação do nosso povo;

f) Promover debates sobre o sistema de cota instituído no país;

g) Ler e recontar com os alunos os seguintes textos:

\section{Reflexões}

\section{Texto 1}

Os balões pretos são igualmente bons

Um pretinho observava 0 homem dos balões na quermesse.

Evidentemente, 0 homem era um bom vendedor pois deixou um balão vermelho soltar-se e elevar-se nos ares, atraindo desse modo, uma multidão de jovens compradores em perspectiva.

Então ele soltou um balão azul, depois um amarelo e, finalmente um branco.

Todos foram subindo cada vez mais até desaparecerem.

0 pretinho ficou bastante tempo olhando o balão preto, aí perguntou:

Moço, se o senhor soltasse 0 balão preto, ele subiria tanto quanto os outros?

0 vendedor de balões deu ao garotinho um sorriso compreensivo.

Partiu o cordão que prendia o balão preto e, enquanto ele se elevava nos ares, disse:

- Não é a cor, filho. É o que está dentro dele que o faz subir.(MELLO, s/d)

\section{Texto 2}

\section{QUEM SOMOS?}

Somos o que somos, alguém apenas 
tentando acertar os passos

no ritmo acelerado da vida.

Como nos tornamos

o que somos?

A nossa história familiar,

as nossas lutas internas e externas,

os nossos sonhos, desejos

e conquistas vão formando

a nossa individualidade.

Nossa identidade é única

marca cada sujeito no mundo

estabelece nossa impressão digital

nos torna um ser singular

e especial.

A cada novo amanhecer

podemos dar um pequeno toque

pessoal no tempo que vivenciamos.

Tempo que passa, passa...

e não volta jamais. (Roseane Maria de Amorim)

\section{Vamos pensar?}

1. 0 que faz nas horas vagas?

2. No seu cotidiano o que faz para tentar melhorar o mundo?

3. Quem é você?

4. Segundo o texto como nos tornamos quem somos?

\section{8- Considerações finais}

Sabemos que a realidade das escolas públicas e até de algumas 
instituições particulares são complicadas devido a violência, as condições estruturais e de vida dos nossos educandos. Entretanto, é na busca e na luta por uma escola de qualidade que conseguiremos incluir os excluídos da sociedade. 0 papel da escola é fundamental para ajudar na formação de seres humanos melhores.

0 ensino da educação étnico-racial é uma dívida histórica que temos para com o nosso povo. É a partir das discussões em diferentes áreas de conhecimentos que os alunos e alunas se sentirão construtores da sua própria história. Nesse sentido, antes de trabalhar as diferentes identidades dos estudantes é preciso que o professor e a professora se identifiquem com a profissão.

A violência, o desrespeito e a exclusão que permeia a sociedade e que está presente no cotidiano escolar tem angustiado os educadores em todo o Brasil. 0 mal- está com a profissão é clara diante da complexidade em que vivemos. Entretanto, a identidade vai se construindo no próprio processo, isto é, nas ações. 0 ser é o que faz e o que sente. 0 olhar para o mundo e para as pessoas que o cercam vão apontando caminhos a serem seguidos e trilhados, cabe a cada educador e educadora acreditar que é possível buscar novas formas de pensar e de ser.

\section{Referências}

BEJAMIN, Roberto Emerson Câmara. A áfrica está em nós: bistória e cultura afrobrasileira. João Pessoa, 2004.

BITTENCOURT, Circe. Identidade nacional. In: KARNAL, Leandro: História na sala de aula: conceitos, práticas e propostas. São Paulo: Contexto, 2003.

. Ensino de História: fundamentos e métodos. São Paulo:

Cortez, 2005.

BRASIL. Ministério da Educação/Secretaria da Educação Continuada, Alfabetização Diversidade. Orientações e Ações para Educação das Relações Étnico-Raciais. Brasília: SECAD, 2006.

MELO, Anthony de,. História de todos dos tempos para mediação. Loyola-Volume 2.

PIRES, Rosane de Almeida Pires. Educação de Jovens e Adultos. In: BRASIL. Ministério da Educação/Secretaria da Educação Continuada, Alfabetização Diversidade. Orientações 
e Ações para Educação das Relações Étnico-Raciais. Brasília: SECAD, 2006.

LOBO, Tancredo. Currículo e identidade na educação. Fortaleza: Livro Técnico, 2005.

KARNAL, Leandro: História na sala de aula: conceitos, práticas e propostas. São Paulo: Contexto, 2003.

ROCHA, Ubiratan. História, currículo e cotidiano escolar. São Paulo, Cortez, 2002.

SANTANA, Patrícia Maria de Souza. Educação Infantil. In: BRASIL. Ministério da Educação/Secretaria da Educação Continuada, Alfabetização Diversidade. Orientações e Ações para Educação das Relações Étnico-Raciais. Brasília: SECAD, 2006.

SCHIMIDT, Maria Auxiliadora; CAINELLI, Marlene. Ensinar História. São Paulo: Scipione, 2004. (Pensamento e ação do magistério).

SOUZA, Ana Lúcia. Ensino Médio. In: BRASIL. Ministério da Educação/Secretaria da Educação Continuada, Alfabetização Diversidade. Orientações e Ações para Educação das Relações Étnico-Raciais. Brasília: SECAD, 2006.

\section{Teaching for ethic and racial relantionship education: a look at school's everday life}

\section{ABSTRACT}

Opening way for the establishment of a broad debate in national level on the questions referring to the situation of the black and the afro-descendent in brazilian society, Act 10.639/2003, that modifies LDB 9694/96, was sanctioned by Federal Government. In this sense, I propose the discussion of the diverse identities of the students from Elementary School up to High School, from the acquisition of values considered negatives fed in day-by-day fo social processes to the consolidation of an afro-centered identity, also valuing the incluision of european and native american roots. This way, this project enables a reflection on the ethnic and racial tutelage of education in the diverse levels of tutelage, in different curricular components and specially on History subject

Key words: Education, Ethic and racial relantionship, History teaching, Curriculum. 